\title{
El silencio como experiencia mística: último refugio de lo genuino y lo libre en un entorno comunicativo
}

Héctor Fabián Pérez Boada

Ministerio de Trabajo, Colombia 


\title{
El silencio como experiencia mística: último refugio de lo genuino y lo libre en un entorno comunicativo*
}

\begin{abstract}
Resumen: en el presente escrito se indaga sobre el concepto del silencio, no solo como un acto de callar sino como una manifestación misteriosa que no se hace verificable en el otro, sino que queda contenida en la particularidad del actor. A partir de allí, se buscará la profundidad casi infinita de dicho proceso humano y cómo este interactúa con el mundo comunicativo de los tiempos de hoy; para así, comprender su existencia como refugio del ser libre de lo externo, suspendido en sí mismo y haciéndose genuino en la cotidianidad de la vida.
\end{abstract}

Palabras clave: silencio, místico, habla interna, libertad, comunicación, ser.

\section{The silence as a mystery experience: the last refuge of the genuine and the freedom of an environmental communication}

\begin{abstract}
: in the research, we look at the concept of silence; not only as the absence of sound or noise, but also as a mystery act that is not provable to the other one. It is just hold by the actor. From that point on, we will search deeply in to this human process and how it gets involved with the communication world of nowadays. Aim at understanding of its existence as a free refuge of the external things, living in itself, and being genuine in the daily life. The Silence as a mystery experience; the last refuge of the genuine and the freedom of an environmental communication.
\end{abstract}

Keywords: silence, mystery, internal speech, freedom, communication, being.

Fecha de recepción: 19 de marzo de 2019

Fecha de aceptación: 3 de julio de 2019

Forma de citar (APA): Pérez-Boada, H. F. (2020). El silencio como experiencia mística: último refugio de lo genuino y lo libre en un entorno comunicativo. Revista Filosofía UIS, 19(1), DOI: 10.18273/revfil.v19n1-2020009

Forma de citar (Harvard): Pérez-Boada, H. F. (2020). El silencio como experiencia mística: último refugio de lo genuino y lo libre en un entorno comunicativo. Revista Filosofía UIS, 19(1), 165-183.

Héctor Fabián Pérez Boada: colombiano. Magíster en Filosofía de la Universidad Industrial de Santander, Colombia.

ORCID iD: orcid.org/0000-0001-8943-9930

Correo electrónico: hperez@mintrabajo.gov.co; hectorfabianp@gmail.com

*Artículo de reflexión derivado de investigación.

Revista Filosofía UIS, vol. 19 n. ${ }^{\circ}$, enero - junio de 2020 


\section{El silencio como experiencia mística: último refugio de lo genuino y lo libre en un entorno comunicativo}

\section{Introducción}

Quiero traer a colación el último aforismo contenido en la obra Tractatus logicophilosophicus del filósofo austriaco Ludwig Wittgenstein que dice lo siguiente: "De lo que no se puede hablar, hay que callar" (2009, p. 137). El autor pretendía, a partir de allí, separar aquello que es comunicable de lo que no se puede decir, poniendo límites al lenguaje posiblemente hasta las fronteras de lo que contiene significado (Santander, 2000). Pero, también, el pensador austriaco deja claro que aquello que no se puede comunicar no se puede afirmar que no exista: "Lo inexpresable, ciertamente, existe. Se muestra, es lo místico" (Wittgenstein, 2009, p. 137). Wittgenstein deja ver cómo el lenguaje se queda corto o sin la posibilidad de que los símbolos gramaticales puedan explicar todo aquello que pareciera indefinible o, más bien, indecible. A esto Wittgenstein lo identifica como lo místico (Wittgenstein, 2009, p. 137) y lo ubica exclusivamente en el espacio del silencio, una manifestación de contenido intrínseco de aquello que no es posible hablarlo porque sencillamente no es argumentable ni razonable y tampoco comunicable (Cordua, 1998).

A partir de la conceptualización anterior, pretendo estudiar estos alcances del silencio confinados en la dimensión subjetiva del individuo como figura única y particular. El concepto del silencio de Wittgenstein, como aquel acto de callar sobre lo que no se puede hablar, conlleva de por sí una aproximación a lo místico, a lo misterioso e intangible; y podemos apreciar cómo, desde esta acción, se concibe un estatus de independencia frente a las fijaciones determinadas por el mundo moderno, alejándose así de todo lo encapsulado en significados; es una válvula de escape para encontrar en el callar un sentido de vida frente a la saturación de lo determinado en el mundo de hoy. Pretendo con este concepto — si es válido fijarlo como tal- ubicar su conexión con la existencia humana y su relación con el mundo moderno, dentro de un proceso propio de la dimensión subjetiva y existencial para darle sentido al ser. 


\title{
2. El juego del lenguaje y el silencio que lo interrumpe como condición existencial
}

Wittgenstein, en su obra Investigaciones filosóficas, expuso lo que se puede entender como el juego del lenguaje:

\begin{abstract}
Nuestros claros y simples juegos de lenguaje no son estudios preparatorios para una futura reglamentación del lenguaje — como si fueran primeras aproximaciones, sin consideración de la fricción y de la resistencia del aire. Los juegos del lenguaje están más bien ahí como objetos de comparación que deben arrojar luz sobre las condiciones de nuestro lenguaje por vía de semejanza y desemejanza (Wittgenstein, 2009, p. 267).
\end{abstract}

Wittgenstein permite apreciar el alcance del lenguaje y su uso desde lo cotidiano, prescribiéndolo específicamente al significante que el ser humano otorga a las palabras, y permitiendo su definición o distinción a partir de su uso; entendiendo que el lenguaje se aprende desde el aprehender (Jaramillo-Herrera, 2004), es decir, "el uso que hacemos de una palabra es su significado" (Carmona, 2015, p. 94). Con esto, Wittgenstein nos arroja hacia el aprecio del lenguaje y su desarrollo en la cotidianidad de la vida de cualquier persona y cómo se define en el campo de la interacción social, mediante la capacidad de comprensión y distinción propia de cada particular. Es a partir de aquel despliegue humano donde nace el uso del lenguaje. Lo anterior permite apreciar que el lenguaje no es fijo ni estático sino, más bien, movible conforme al mundo de las percepciones y del ejercicio cognitivo y emocional de cada particular, que surgen con base en nuestra cotidianidad. Así lo apreció Wittgenstein:

El niño aprende a creer muchas cosas. Esto es, aprende por ejemplo a actuar de acuerdo con estas creencias poco a poco, se forma un sistema con las cosas que cree y, en tal sistema, algunos elementos se mantienen inmutables y firmes, mientras que otros son más o menos móviles. Lo que se mantiene firme lo hace no porque intrínsecamente sea obvio o convincente, sino porque se sostiene en lo que le rodea (Wittgenstein, 2009, p. 683).

A partir de las anteriores apreciaciones nace un interrogante en referencia a si la postura sobre lo cotidiano, que Wittgenstein fijó en relación al lenguaje, puede ser aplicable para el acto de callar, es decir, ¿en la cotidianidad es posible apreciar la existencia del silencio? Su existencia está sobreentendida pero no se le presta la debida atención. Por ejemplo, en el mismo juego del lenguaje, el silencio se tiene como un acto necesario que permite la comunicación de las palabras, pero no se le presta la debida atención porque se tiene por sobreentendido. Lo anterior hace referencia a cuando en el desarrollo comunicativo de hacer una lectura o de hablar con otra persona podemos apreciar los significantes de las palabras gracias 
a las pausas que desarrollamos para fijar la distinción propia de cada una de estas; es decir, hacemos uso de los signos ortográficos y de puntuación, sin estos las palabras pueden perder su esencialidad en el juego del lenguaje que no es otro que el permitir apreciar en el otro el significado de las palabras (Wittgenstein, 2009, p. 407). Pero estos silencios generados por los signos de puntuación se dan por sobreentendidos; es decir, solo aparecen cuando se omiten, demostrando así la necesidad del silencio en el juego del lenguaje y demostrando que existen por necesidad y que hacen parte del juego del lenguaje; por lo que la necesidad de callar se hace vital para la consecución del hablar como forma para expresar un significado; por lo tanto, si el silencio le da sentido al lenguaje cabe decir que, dentro del mundo de las posibilidades, el silencio también puede darle sentido a la vida. ¿Es esto posible? Deseo apreciar si el uso del silencio no solo sirve como una herramienta de la cotidianidad del lenguaje sino también como un estilo de vida en el quehacer humano, como un proceder propio del fuero interno de cada individuo.

Para cumplir con tal finalidad creo que es pertinente adelantar su análisis desde las posturas del lenguaje dadas por el pensador austriaco. En primer lugar, queda claro que mediante el uso del lenguaje se pueden comunicar significados y, en segundo lugar, que este trámite comunicativo se desarrolla gracias al espacio temporal de la cotidianidad de cada persona, por lo tanto, el aprehender en el lenguaje se obtiene desde la cotidianidad, es por ello que el proceso del lenguaje no es estático sino movible; ahora al ser movible puede llevar de por sí a cambios, es decir, que el significable de una palabra puede variar en el tiempo gracias al proceso de lo cotidiano; esto quiere decirnos que una misma palabra puede tener dos significados en diferentes periodos de tiempo, tal como lo afirma el mismo Wittgenstein: "Por otra parte, el juego del lenguaje cambia con el tiempo" (Wittgenstein, 2009, p. 709).

Ahora, al ser el lenguaje movible desde su uso, puede llevar también a cambios en las opiniones del sujeto que comunica. Debe comprenderse que el lenguaje se exterioriza al igual que la opinión particular de cada sujeto; sin embargo, la variación de significados o de opiniones conlleva una relación tanto de lo externo como del fuero interno, entendiendo lo último como aquel espacio privado y secreto del individuo donde se produce la modificación del significable o de la forma de pensar. Lo anterior lo podemos comprender en un pasaje escrito por el mismo Wittgenstein:

¿Debo decir que quien tiene una intención experimenta una tendencia? ¿Que hay ciertas vivencias de tendencia? —acuérdate de este caso: cuando en una discusión alguien quiere hacer urgentemente una observación, una objeción, ocurre a menudo que abre la boca, aspira aire y retiene la respiración; si se decide por dejar de hacer la objeción, espira el aire. La 
vivencia de este proceso es evidentemente la vivencia de una tendencia a hablar. Quien me observe se dará cuenta de que yo quería decir algo y luego cambié de idea (Wittgenstein, 2009, p. 491).

Wittgenstein nos muestra cómo la tendencia de hablar puede, posteriormente, transformarse en una tendencia a callar; el pensador austriaco nos recrea la escena de una persona que desea hacer una objeción y posteriormente renuncia a esta, elección que tomó no desde lo comunicable sino desde un proceso propio del fuero interno; donde solo se conoció por los otros el resultado final que fue la decisión de no hablar, pero difícilmente se hizo conocible lo que motivó tal variación en su opinión, quedando recluidos bajo el incógnito y el misterio detrás del acto de callar; con esto Wittgenstein nos muestra cómo el silencio no solo existe para darle sentido a las palabras sino también para contener y hasta ocultar las opiniones.

Ahora la variación en la opinión se hizo percibible gracias al proceso de lo cotidiano, de lo movible en donde se pudo verificar la relación existencial entre el uso del lenguaje (tendencia de hablar y de callar) y el acto de silencio (temporalidad que conectó a las dos intencionalidades); pero no se manifestó el motivo que llevó al cambio de tendencia; encontramos aquí que en el silencio, como aquel que contiene al fuero interno, se convierte en punto de partida de puede ser condicionante de lo que queremos exteriorizar; es decir, lo incógnito puede ser causal de lo determinado, siempre y cuando no dé a conocer las razones que motivaron la tendencia a callar.

Pero ¿qué es el silencio?, o más bien, ¿qué puede producirse en este o qué se contiene en el proceso de callar? Creería que no solo es el contenedor de lo que se pretende decir o ser parte del proceso comunicativo de las palabras para darle funcionalidad a los signos de puntuación, sino mucho más y es la tarea principal del presente artículo verificar todo aquello que es contenible en el acto de hacer silencio y ahondar sobre su real esencia en los tiempos presentes donde pareciera que todo se volvió comunicable.

\section{Los contenidos del silencio según Wittgenstein}

En el capítulo anterior descubrimos el silencio como aquella acción integrada en el juego del lenguaje que permite darle sentido a las palabras que decimos, pero también como un proceso de interrupción (de la tendencia de hablar a la tendencia de callar); pero lo que intriga es iqué reside en aquel acto de interrupción? Se tratará de dar respuesta a este interrogante, trayendo a colación un párrafo contenido en el libro Investigaciones Filosóficas del pensador austriaco que dispone: 


\begin{abstract}
Cuando para mis adentros me repito el $\mathrm{ABC}$, ¿cuál es el criterio para decidir que hago lo mismo que otro que se lo repite a sí mismo en silencio? Podría hallarse que ocurre lo mismo en mi laringe y en la suya. (E igualmente cuando los dos pensamos lo mismo, deseamos lo mismo, etcétera.) Pero zaprenderíamos el empleo de las palabras «repetirse eso o aquello en silencio» indicando un proceso en la laringe o en el cerebro? ¿Acaso no es posible también que a mi imagen del sonido a y a la suya les correspondan procesos fisiológicos distintos? La cuestión es: icómo se comparan imágenes? (Wittgenstein, 2009, p. 407).
\end{abstract}

Wittgenstein afirma que el silencio es lo que se oculta en la interioridad del ser, como algo impenetrable para el otro y solo puede darse a conocer cuando se exterioriza; es decir cuando se vincula al juego del lenguaje. Es por ello que, para el pensador Austriaco, el silencio tiene estrecha relación con lo místico (Cordua, 1998, p. 244) como aquel espacio-temporal donde se contiene el misterio; radicando allí una temporalidad del ser libre, un momento propio y privado para elegir, que solo culmina con toda intención de exteriorización, de manifestación, del mostrar; callando la libertad cuando se deja de hacer silencio. Un misterio que busco ahondar y profundizar desde su contenido.

Wittgenstein escribió sobre el silencio de manera muy breve en sus obras, pero a partir de allí es donde esperamos encontrar respuesta al interrogante fijado en líneas anteriores. Podemos empezar por aquello que él llamó el habla interna: el hablar interno no es otra cosa que el hablar desde el silencio (Wittgenstein, 2009, p. 407), no como un fenómeno de lo oculto sino como una acción comunicable, ya que mediante el habla interna los otros pueden apreciar cómo se inervan los músculos de la laringe o cómo sigue la vista en las páginas de un libro; es por ello que no es un proceso del todo escondido sino algo que se manifiesta (puedo cantar internamente, leer en silencio, o calcular de memoria): "«Pero el habla interna es sin duda una actividad determinada que debo aprender.» Ciertamente; ¿pero qué es aquí ‘hacer' y qué es 'aprender'?" (Wittgenstein, 2009, p. 613).

Esta primera forma de silencio se identifica como un despliegue particular y exclusivo del individuo que permite la manifestación de los gestos de quien habla de manera interna; pero no se llega a conocer el contenido de su silencio así lo presumamos ya que, como lo dice Wittgenstein, el habla interna es una actividad determinada, es decir, supone que parte de elementos existentes, definidos y conceptuados como la letra de una canción que se recita, los párrafos plasmados en un libro que se lee, o los símbolos conocibles de las matemáticas; un despliegue interno a partir de lo que ya cuenta con un significado pero que se comunica sin el uso de la voz. Este es el primer silencio que enseña el filósofo austriaco desde la cotidianidad y desde el juego del lenguaje. 
Lo interesante de esta actividad del habla interna es que está acompañada de una actitud imperceptible en el otro. Wittgenstein explica que tal habla interna viene acompañada del proceso de la imaginación, evento necesario para que tal silencio pueda configurarse como una acción determinada:

\begin{abstract}
Podemos hablar en la imaginación muy 'claramente' cuando al hacerlo zumbamos el tono de las frases (con los labios apretados). También contribuyen a ello los movimientos de la laringe. Pero lo curioso es justamente que entonces oímos el discurso en la imaginación y no sólo sentimos, por así decir, su esqueleto en la laringe. (Pues también podríamos imaginar que los seres humanos calcularan en silencio con movimientos de la laringe, así como podemos calcular con los dedos) (Wittgenstein, 2009, p. 613).
\end{abstract}

Ahora, valdría la pena indagar ¿qué pasaría en el silencio sin el ejercicio de la imaginación?, es decir ipodríamos hablar de la posibilidad de silenciar hasta la imaginación? Tales interrogantes nos acercan a la puerta de entrada al acápite de la presente investigación que nació gracias al numeral siete del Tractatus logico-philosophicus que dice: "De lo que no se puede hablar hay que callar" (Wittgenstein, 2009, p. 137). El interés sobre este aspecto no radica tanto sobre si es factible callar, es decir, hacer silencio acerca de aquello sobre lo que, desde el lenguaje, se puede hablar; sino todo lo contrario: ¿se puede hacer silencio sobre lo que no se puede hablar? y isi de lo que no se puede hablar tiene alguna relación con la capacidad de imaginar?

En el mismo Tractatus (numeral 3.1431) expone el autor lo siguiente: "Muy clara resulta la esencia del signo proposicional cuando, en lugar de imaginárnoslo compuesto de signos escritos, nos lo imaginamos de objetos espaciales (como, por ejemplo, mesas, sillas, libros)" (Wittgenstein, 2009, p. 23).

Allí el autor aborda el tema de la esencia del signo proposicional, como aquello que se encuentra contenido en el ejercicio de la imaginación y no es otra cosa que hechos (Wittgenstein, 2009, p. 21), pero iqué tipo de hecho? La respuesta se encuentra en el párrafo 3.14 del mismo libro, en el cual el signo proposicional está constituido por elementos que no son otros que las palabras, aquellas que están, según el autor, más o menos determinadas. El Tractatus muestra cómo la comunicación se desprende de las proposiciones, estas que configuran los signos proposicionales y que permiten en el receptor el proceso de imaginar hechos como aquellos que pueden expresar un sentido (Wittgenstein, 2009, p. 21).

Lo anterior indica que, si la imaginación es la esencia del signo proposicional gracias a que conduce a la comunicación, entonces, sin la imaginación no es posible comunicar, al menos para el receptor sería una situación difícil y complicada en el proceso de comprensión. Por lo tanto, de lo que no se puede hablar es de todo 
aquello que no se puede imaginar; a eso hace referencia el pensador austriaco en su obra Investigaciones filosóficas en donde afirmó:

Podemos hablar en la imaginación muy 'claramente' cuando al hacerlo zumbamos el tono de las frases (con los labios apretados). También contribuyen a ello los movimientos de la laringe. Pero lo curioso es justamente que entonces oímos el discurso en la imaginación y no sólo sentimos, por así decir, su esqueleto en la laringe (Wittgenstein, 2009, p. 613).

La comunicación, así sea solo para sí mismo — cuando se hace referencia al habla interna-, solo es posible mediante la imaginación, ya que a través de ella se les da sentido a los signos proposicionales. Es por ello por lo que, para Wittgenstein, lo que está oculto a la imaginación no es posible comunicarse:

El hecho de que lo que otro habla internamente me esté oculto radica en el concepto 'hablar internamente'. Sólo que «oculto» es aquí la palabra errónea; pues si a mí me está oculto, a él mismo le debería ser evidente, él debería saberlo. Pero él no lo 'sabe', sólo que la duda existe para mí no existe para él [...] «Lo que alguien se dice a sí mismo en su interior me está oculto» (Wittgenstein, 2009, p. 613).

Con todo lo anterior queda claro, para Wittgenstein, que el silencio como habla interna es una manera de comunicar — consigo mismo- y como tal, es posible mediante la imaginación y los signos proposicionales para que se consiga la comprensión o consecución de los significados. Pero lo que resulta difícil es la posibilidad de un silencio sin la intervención de la imaginación, que para Wittgenstein no es posible si se acoge a la proposición "De lo que no se puede hablar hay que callar" (2009, p. 137). Esto quiere decir que no solo el lenguaje tiene sus límites —en el entendido que solo puede comunicarse aquello que tiene significado- sino también que el ejercicio del silencio puede depender exclusivamente de la imaginación. Sin embargo, cabría preguntarse: ipuedo ponerle límites a la capacidad de imaginar?, o iesta se condiciona a todo lo existente? Wittgenstein direcciona su teoría a un proceder imaginativo en donde se cancela todo propósito metafísico y, así mismo, toda inquietud sobre lo trascendental. Pero tal pretensión queda suspendida con otra frase del Tractatus que se ha mencionado en líneas anteriores, la cual es pertinente volver a traer a colación: "Lo inexpresable, ciertamente, existe. Se muestra, es lo místico" (Wittgenstein, 2009, p. 137).

Es una confrontación entre lo expresable con aquello que no es posible comunicar dentro de los cánones del lenguaje, algo que el filósofo austriaco llamará lo místico. Es así que, lo místico, es todo aquello que escapa de las fronteras de los signos proposicionales y de la misma imaginación, o donde aquel imaginar no puede superar las fronteras de lo determinado; por ejemplo, cuando hablamos de 
un unicornio, la imaginación nos lleva a retratar desde los determinables (es decir, los significados); en este caso un caballo y un cuerno. Es por ello que lo místico no es comunicable, al no ser posible fijarlo dentro de los significados existentes ni hacer uso de la imaginación; es decir, entramos en lo que llamamos trascendental. En el Tractatus se encuentran dos numerales en donde se hace referencia sobre lo trascendental, delimitándolo exclusivamente al campo de la lógica y la ética. Primero en relación a la lógica, en el numeral 6.13 se afirma lo siguiente: "La lógica no es una teoría sino una figura especular del mundo. La lógica es trascendental" (Wittgenstein, 2009, p. 121).

Wittgenstein ubica a la lógica como una ciencia de lo especulativo, desdeñándola hacia lo improbable y sobre supuestos. Ahora, al ser la lógica algo trascendental, podemos afirmar que lo trascendental supera las fronteras de los determinables, es decir los significados. Estos presupuestos de lo trascendental también los fija en la esfera de lo ético, específicamente en el numeral 6.421 del Tractatus que dice: "Está claro que la ética no resulta expresable. La ética es trascendental" (Wittgenstein, 2009, p. 133), a través de esta proposición nos muestra nuevamente que lo ético es trascendental por ser inexpresable; pero tal trascendencia al no ser comunicable no quiere decir que no existe sino únicamente indica que escapa de los parámetros del lenguaje. A partir de lo anterior, es factible relacionar lo trascendental con lo místico, o más bien manifestar que lo trascendental es lo místico por ser inexpresables y especulativos. A partir de lo anterior vale preguntarse: ¿en el silencio cabría lo místico?, es decir, si en el acto de callar se puede contener lo trascendental y especulativo, en una palabra, lo que no es comunicable. Este será el tema por tratar a continuación.

\section{El silencio y lo místico según Wittgenstein}

En el capítulo anterior, gracias a la proposición 6.522 del Tractatus, se pudo apreciar cómo lo místico y lo trascendental no son comunicables, donde Wittgenstein creía que estos no son temas aplicables en el uso del lenguaje ${ }^{1}$. Sin embargo, Wittgenstein también comprendió como lo místico y lo trascendental, aunque no son comunicables, si se experimentan, pero donde dicha experimentación es algo inexpresable (Tractatus 6.522: se muestra, es lo místico), pero en esencia iqué es lo místico? En el libro sobre la certeza de Ludwig Wittgenstein se hace una referencia a este concepto: “¿Habría de ser una creencia supuestamente científica? ¿No podría ser una creencia mística? Con ello, ¿̇ha de estar en total contradicción con los hechos históricos o, incluso, geográficos?" (Wittgenstein, 2009, p. 703).

\footnotetext{
1 "Pues en el Tractatus se habla principalmente de la forma de figuración del mundo por medio del lenguaje y de la verdad de dicha forma, de modo que verdad y sentido se relacionan. Precisamente el sentido descansa en la función figurativa del lenguaje, pues las únicas proposiciones con sentido, según Wittgenstein, son aquellas que expresan un estado posible de cosas" (Cadavid, 2014, p. 130).
} 
Para Wittgenstein lo místico solo se encuentra en el campo de lo creíble, porque no hace parte del mundo de los hechos ni de la ciencia; por lo tanto, lo creíble puede prescribirse dentro del espectro de lo no comunicable. Ahora, es pertinente, primero que todo, entender a que hace referencia el concepto de lo místico para luego relacionarlo con los postulados dado por Wittgenstein; entonces, desde su sentido léxico lo místico es:

[...] mystica: Aunque muchas veces aparece con la grafía mística, esta voz conserva en el período patrístico y en el medieval, la forma que evoca su origen griego: proviene de my- que alude a lo cerrado, más específicamente, poner el dedo sobre la boca para cerrarla en señal de silencio, de donde mýein que significa cerrar ojos y boca, y de allí myeîn, iniciar en los misterios, o sea, en algo secreto, arcano (Magnavacca, 2005, pp. 445-446).

La anterior definición sobre lo místico se relaciona con el concepto de lo oculto, Wittgenstein hace una apreciación sobre lo oculto en el libro Investigaciones Filosóficas:

El hecho de que lo que otro habla internamente me esté oculto radica en el concepto 'hablar internamente'. Sólo que «oculto» es aquí la palabra errónea; pues si a mí me está oculto, a él mismo le debería ser evidente, él debería saberlo. Pero él no lo 'sabe', sólo que la duda que existe para mí no existe para él (Wittgenstein, 2009, p. 613).

El pensador austriaco busca diferenciar entre lo que él denominó habla interna y lo que está oculto, ya que, para quien hablar internamente no le está oculto lo que se contiene en ese silencio sino todo lo contrario, lo conoce; claro está, que dicha exclusividad culmina hasta cuando lo exterioriza en el otro, en el mundo. Pero, para Wittgenstein, lo oculto se dirige más bien hacia la imposibilidad de conocerlo por todos, hasta para sí mismo². Hasta ahora podemos comprender que lo místico hace referencia a lo que está cerrado, secreto, oculto, simbolizado mediante el acto de poner el dedo sobre la boca y el cerrar los ojos.

Para Wittgenstein lo místico no es un hecho, ya que solo los hechos caben en el conocimiento. En el Tractatus él afirma que "No cómo sea el mundo es lo místico, sino que sea" (2009, p. 135); a partir de esto, la experiencia de lo místico no se genera gracias a situaciones concretas que se den en el mundo; ya que en el mundo no hay otra cosa que hechos; pero en lo místico el mundo se toma como un todo ${ }^{3}$.

\footnotetext{
${ }^{2} \mathrm{Al}$ respecto ha dicho Wittgenstein: "El hecho de que lo que otro habla internamente me esté oculto radica en el concepto "hablar internamente'. Sólo que «oculto» es aquí la palabra errónea; pues si a mí me está oculto, a él mismo le debería ser evidente, él debería saberlo. Pero él no lo 'sabe', sólo que la duda que existe para mí no existe para él" (2009, p. 613).

${ }^{3}$ Véase Wittgenstein, 2009, p. 135: “La visión del mundo sub specie aeterni es su visión como-todolimitado. El sentimiento del mundo como todo limitado es lo místico".
} 
Hasta este punto es posible afirmar que todo lo místico son hechos ocultos, pero no todos los hechos ocultos hacen parte del campo de lo místico ya que existen hechos escondidos como el habla interna. El filósofo austriaco es claro en decir que un hecho puede estar oculto teniendo en cuenta que no se ha manifestado; es decir no se ha dado a conocer; entonces existen hechos ocultos e igualmente lo místico es oculto por lo que cabe preguntarse ¿̇uál es la particularidad para que aquello que está oculto sea místico y no un hecho?

Ya hemos afirmado que lo místico se muestra (Wittgenstein, 2009, p. 137), que por lo tanto se experimenta, pero iqué quiere decir esto? No es otra cosa que lo místico tiene la capacidad de experimentarse más no de perder el sentido de lo oculto; ya que, si se elimina, podríamos decir que deja de ser misterioso y por ende puede ser comunicado. Wittgenstein lo deja claro cuando habla de aquello que define como vivencias internas:

¿Pero sería también imaginable un lenguaje en el que uno pudiera anotar o expresar sus vivencias internas —sus sentimientos, estados de ánimo, etcétera- para su uso propio? - ¿Es que no podemos hacerlo en nuestro lenguaje ordinario? - Pero no es eso lo que quiero decir. Las palabras de este lenguaje deben referirse a lo que sólo puede ser conocido por el hablante, a sus sensaciones inmediatas, privadas. Otro no puede, por tanto, entender este lenguaje (Wittgenstein, 2009, p. 347).

Aquí se entiende que existen cosas que se pueden experimentar mas nunca comunicarse, como son las vivencias internas, los sentimientos, los estados de ánimo. En lo místico pasa lo mismo; puede sentirse mas nunca puede describirlo dentro de los significados del lenguaje. Esto es lo que hace diferente lo oculto de un hecho y de lo oculto en lo místico; que en el primero se puede comunicar y deja de serlo, mientras que en el segundo no y por lo tanto no pierde su misterio. Por lo tanto, al no poderse comunicar lo místico no queda otro terreno donde residir que, dentro del entorno humano, en su silencio; pudiendo afirmar entonces que el silencio contiene a lo místico al momento de vivir una experiencia particular que nunca es exteriorizada por parte del actor. Pero si lo místico no es comunicable, es oculto, misterioso, cabría decir que hasta lo infinito podría manifestarse allí; entendiendo lo infinito como aquello que no le pone límites a la imaginación utilizada o prescrita en el juego del lenguaje ${ }^{4}$.

\footnotetext{
4 "El rechazo de la identidad excluye un método de hablar de la totalidad de las cosas, y se encontrará que cualquier otro método que se proponga ha de resultar igualmente engañoso; así, al menos, lo afirma Wittgenstein, y yo creo que con fundamento. Esto equivale a decir que «objeto» es un pseudoconcepto. Decir que «x es un objeto» es no decir nada. Se sigue de esto que no podemos hacer juicios tales como «hay más de tres objetos en el mundo» o «hay un número infinito de objetos en el mundo». Los objetos sólo pueden mencionarse en conexión con alguna propiedad definida" (Wittgenstein, 2009, pp. 147-148).
} 
Ahora, el silencio al ser una acción individual cuenta con unos límites temporales — cuando comienzo y finalizo el proceso de callar-; por lo que es de difícil comprensión que en el silencio (finito) pueda caber lo místico (infinito), por lo que no se podría hablar explícitamente de un contenido sino únicamente de un contacto; es decir, en el silencio, como experiencia mística, es posible un encuentro con aquello oculto e incomunicable debido a que no existen las barreras del lenguaje.

Es así que en el silencio no solo se experimenta como habla interna sino también la vivencia de lo místico y lo misterioso e infinito; en donde el último no es posible comunicarse debido a la imposibilidad de darlo a conocer a los otros mediante los significados. Pero al no ser comunicable la experiencia mística; valdría preguntarse ide qué sirve vivir momentos místicos si no puedo darlos a conocer al otro? Para dar respuesta a esta inquietud es pertinente estudiar lo comunicable del acto de callar, no desde el lenguaje sino desde la experiencia misma -teniendo en cuenta que lo místico fue definido por Wittgenstein como experiencia- o verificar si dicho proceso vivencial queda totalmente suspendido en el interior del individuo. Tal correlación permitirá verificar sus efectos en el ente individual confrontado con el mundo.

\section{El silencio y la acción comunicativa en el mundo actual}

Hemos comprendido, a través de Wittgenstein, que el silencio como experiencia mística no se puede comunicar a partir del juego del lenguaje; sin embargo zaunque no se comunica es posible exteriorizarlo del entorno individual? Para Wittgenstein obviamente no es posible, pero creo en la pertinencia de verificarlo a través, no del juego del lenguaje, sino de la acción comunicativa; teniendo en cuenta que el silencio como acto humano es percibible, independientemente de lo que se calla. Para ello se estudiará el tema desde la óptica filosófica de Jürgen Habermas, quien ha enfocado sus estudios a la comunicación de la siguiente manera:

El concepto de racionalidad comunicativa remite, por el primer lado, a las diversas formas de desempeño discursivo de pretensiones de validez (por eso habla Wellmer también de racionalidad «discursiva»); y por el otro, a las relaciones que en su acción comunicativa los participantes entablan con el mundo al reclamar validez para sus manifestaciones o emisiones; de ahí que la descentración de la visión del mundo se haya revelado como la dimensión más importante de la evolución de las imágenes del mundo (Habermas, 1985, p. 111). 
Habermas habla de dos conceptos: el de la racionalidad comunicativa y el de la acción comunicativa. En el primero hace referencia a las formas a través de las cuales el ser humano busca, con su discurso lingüístico, asegurar la validez de sus pretensiones ${ }^{5}$, mientras en el segundo no busca la validez de las pretensiones sino de sus manifestaciones o emisiones.

Se puede entender a la acción comunicativa como aquella que busca más que validar conceptos o argumentos, su meta es compartir, dar a conocer experiencias, que lleva a quien recibe tal acción al acuerdo o desacuerdo de esta ${ }^{6}$. Pero cuando hablamos sobre el acuerdo o el desacuerdo de la experiencia compartida, se hace referencia a si este es comprensible, entendible, más que a aceptarlo como verdad. El profesor Francisco Sierra entiende la acción comunicativa de la siguiente manera:

La acción comunicativa se entiende como una acción social orientada a compartir el sentido mediante la experiencia, el entendimiento, el acuerdo y las decisiones mutuas, en torno al mundo de la naturaleza externa, a nuestro espacio de relaciones culturales y sociales, y en torno a nuestro mundo interior e individual... Acción social que ha de validarse si hablante/ oyente, escritor/lector, optan por, reconocen, se exigen mutuamente y logran satisfacer exigencias de verdad y argumentación racional, cuando se refieren a los hechos en actitud objetivante y cognitiva (Sierra, 1988, p. 139).

Es posible comunicar al otro no solo aquello que se puede denominar como razonable, sino también experiencias, sentimientos, entre otros. Ahora, es pertinente verificar la posible relación entre lo comunicable y aquello que se puede llamar como lo cotidiano. Hortensia Cuéllar, en su artículo denominado "Hacia un nuevo humanismo: Filosofía de la vida cotidiana", acoge el concepto de lo cotidiano como "[...] lo común, a lo familiar, a lo de todos los días. En este sentido vida corriente, vida cotidiana, vida ordinaria, indican lo mismo" (Cuéllar, 2009 , p. 2). Lo cotidiano hace referencia a todo aquello que se hace todos los días, en el diario vivir, ya sea por costumbre, por necesidad o por obligación. Es decir, lo cotidiano se relaciona con el quehacer en el diario vivir, donde una de las actividades cotidianas del ser humano es comunicarse, ya sea para dar a conocer un significado, una proposición racionalmente válida o una situación de experiencia particular.

\footnotetext{
"El primer objetivo de la Teoría de la Acción Comunicativa se cumple a través del análisis del concepto filosófico moderno y clásico de razón, así como de las estructuras sociales vinculadas a lo que puede ser válido como "racional". El propósito de Habermas es presentar el programa de una racionalidad "comunicativa" que, teóricamente, se deriva de la constitución de la "intersubjetividad" (Solares, 1996, p. 10).

6 "Al mismo tiempo, Habermas complementa estas dos dimensiones de la racionalidad —la instrumental y la comunicativa - con la dimensión racional estético-expresiva; lugar donde la relación "auténtica" de los sujetos apunta al mundo de sus sensaciones y experiencias internas" (Solares, 1996, p. 14).
} 
Con Habermas todas las experiencias son comunicables pero con Wittgenstein no, donde excluye aquellas que no se pueden imaginar, que no se pueden comprender a partir de los significados conocidos. El litigio al que nos arroja todo el estudio que hasta el momento se ha desarrollado es si el silencio como experiencia es comunicable.

En principio hemos comprendido que existen situaciones que no son comunicables porque se mantienen ocultas o no se exteriorizan: "Incomunicación en el silencio, lo desconocido, el secreto, la intimidad, con ella expresamos y reconocemos las insalvables diferencias entre nosotros; la libertad de sentimiento, pensamiento y acción inédita en uno y en los otros" (Sierra, 1988, p. 138).

Nace aquí un nuevo interrogante y hace referencia a si la experiencia mística, vivida en el silencio, siempre se mantendrá incomunicada a los demás. El filósofo alemán Habermas, aunque en su obra no hace referencia al silencio, sí se refiere a lo incomprensible como aquello que no resulta racionalmente válido en el proceso comunicativo, el individuo está ante la posibilidad de renunciar o no en su clarificación hermenéutica (Habermas, 1985, p. 84). Lo comunicativo, según Habermas, lleva consigo la posibilidad de ser compartido con el otro y queda la tarea de ser comprendido, entendido y aceptado.

Tanto para Habermas como para Wittgenstein la experiencia es comunicable, siempre y cuando existan los significados para darlo a entender al otro. Lo anterior nos indica que es posible comunicar mi silencio únicamente como acto, ya que el otro entiende y aprecia cuando una persona está haciendo silencio, como es el caso del habla interna. Pero ìlo místico? Cuando una persona ejerce el acto de callar, solo es posible conocerlo y comprenderlo cuando se deja de hacer silencio, es decir, cuando se exterioriza y se reconoce su contenido, lo cual no es fácil para aquello que llamamos misterioso.

Hemos visto cómo en el silencio puede residir tanto el habla interna como la experiencia mística; en donde se contienen tanto lo que tiene significado como aquellos que no lo son. Ahora, solo puede exteriorizarse aquello que se pueda comunicar; es decir, que pueda ser comprendido a través de los signos proposicionales, por lo que lo misterioso (como aquello que no tiene significado que lo contenga) es difícil de comunicar; sin embargo, ¿cómo nacen nuevos significados? Mi pregunta va dirigida a cómo nacen nuevas palabras; por ejemplo, términos como internet o celular que hace doscientos años eran incomprensible dentro del proceso comunicativo y por ende misterioso. Wittgenstein afirma acerca de los signos proposicionales que otorgan un nuevo sentido:

4.026. Los significados de los signos simples (de las palabras) deben sernos explicados para que nos sea posible entenderlos. Pero con las proposiciones nos comprendemos. 4.027. Pertenece a la esencia de la proposición poder 
comunicarnos un sentido nuevo. 4.03. Una proposición debe comunicar un sentido nuevo con expresiones viejas.

La proposición nos comunica un estado de cosas; tiene, pues, que estar esencialmente conectada con el estado de cosas (Wittgenstein, 2009, p. 39).

Tales proposiciones que revelan un sentido nuevo deben residir en primer lugar en el silencio de su autor, su creador; porque es en este espacio donde se es permisible la novedad, aquello que no existe dentro lo comunicativo, sino que se hace nuevo para hacerse comunicable, comprensible y entendible. A esto llamo lo genuino en el silencio; lo nuevo que nace en el entorno propio del silencio pero que luego se hace legítimo en el contexto social; pero este sentido de lo nuevo se configura gracias a que en el espacio temporal del silencio individual no se prescribe únicamente bajo los significados existentes sino todo lo contrario; allí estos conviven con todo lo que los supera. Además, lo genuino en el silencio hace referencia a la existencia de un espacio libre, entendiéndolo como la posibilidad de imaginar sin límites; una imaginación no prescrita a los signos proposicionales sino todo lo contrario, superándolos. Apreciamos aquí, cómo el silencio — conforme a los postulados wittgenstenianos- es el espacio único y particular donde conviven lo definible con lo misterioso, lo comunicable con lo místico; a partir de lo anterior vemos una relación rara y extraña pero que acentúa la originalidad y lo libre del ser; de donde nace la novedad, el sentido nuevo de los signos proposicionales, donde se puede pensar sin límites y sin objeciones - como nadie lo conoce, no hay oportunidad de ser tachado de falso o errado por el otro-, es un espacio donde es permisible hacer uso de los significados para tratar de comprender la experiencia mística y, por el otro lado, es una temporalidad donde se puede ampliar los signos proposicionales sin descartar la ayuda o apoyo de lo misterioso. Es en el silencio donde nacieron las historias de superhéroes con nuevos significados; donde dimos sentido a lo irreal; como un hombre que vuele con una capa o una mujer se haga invisible. Pero ¿̇uál debe ser la funcionalidad o la esencia misma del silencio como experiencia mística para el individuo del mundo de hoy?

\section{El silencio como proceso cotidiano dentro del mundo actual de lo comunicable}

Hemos visto cómo el silencio es el espacio temporal particular donde convive el habla interna y la experiencia mística, en donde solo se hace comunicable aquello prescribible a significados. Así mismo, se definió el concepto de lo comunicable, como una acción donde el ser humano comparte palabras y experiencias que se hacen comprensibles por el otro. Igualmente se comprendió el concepto de lo cotidiano como el quehacer diario. Sin embargo ¿cómo relacionar lo comunicable con el silencio desde lo cotidiano? 
Cuando se habla de una experiencia hacemos referencia a un suceso o eventualidad donde se presenció, se percibió o se conoció algo. Ahora, Habermas no negó la posibilidad de que las experiencias sean comunicables, siempre que sean manifestables, es por eso que el silencio es comunicable, pero desde lo que exterioriza - es decir, el acto de callar-; como el caso del habla interna, en la cual se percibe la acción de susurrar con los labios, ya sea para leer o para hacer cálculos en silencio, pero se desconoce su contenido. Igualmente, para Wittgenstein es comunicable el silencio como acción porque, dentro de los significados, existe lo que entendemos por el acto de callar, independiente de lo que se esconda detrás de este.

Pero en relación al silencio como experiencia mística, Wittgenstein dejó manifiesto que es una expresión de vivencias internas que no se hacen comunicables desde el lenguaje, algo que igualmente comprendió Habermas que, desde la acción comunicativa, se puede apreciar el acto de callar mas no el contenido del silencio. Queda claro entonces que el acto de callar — como hecho- es comunicable, sin entrar a mirar si este se realiza como proceso de habla interna o como experiencia mística; pero ya el contenido intrínseco no lo es; es por eso que la situación mística dentro de la experiencia del silencio no es comunicable; entonces iqué tipo de relación puede existir entre el silencio como experiencia mística y lo comunicable?, el silencio como experiencia mística no es comunicable, pero puede ser causa de actos comunicables.

Igualmente, a través de la experiencia mística el ser humano particular, autor de dicha vivencia interna, puede construir nuevos sentidos a signos proposicionales como el de la teoría de la gravedad — que nació de una experiencia particular y exclusiva de Isaac Newton quien vio caer la manzana mientras trabajaba en unos experimentos (El Espectador, 4 de abril de 2018)—; pero también puede que el acto de hacer silencio motive otras acciones; como por ejemplo cambios de hábitos y modificaciones en la forma de pensar, reformulando conceptos y hábitos cotidianos, entre otros eventos (en las religiones a este proceso se le identifica como conversión), por lo tanto, el silencio como acción se hace comunicable y es motor de otras acciones comunicables, así su contenido no se conozca y parta de causas místicas.

Apreciamos aquí la única y posible relación existente entre el silencio místico y el acto comunicable a través de la cotidianidad, en el cual no conocemos el misticismo interno sino el acto de callar, pero también se descubre cómo la experiencia mística contenida en el silencio puede ser causa o motor de acciones comunicables gracias a la convivencia libre y genuina de lo misterioso con lo que tiene significado en el contexto particular del acto de callar. El acto de callar es una invitación al proceso reflexivo de lo determinable y lo místico. Una relación profunda pero aceptada por quien calla, en donde lo indeterminado puede ser 
causa de lo determinable, y lo significado busca darle contenido proposicional a lo misterioso; propósitos que permiten la consecución de la novedad.

Al ser el silencio, como experiencia mística, causa de situaciones comunicativas, no debe ser descartado como fórmula de vida, ya que no es posible excluirlo como motor dentro de los propósitos individuales del ser humano, más cuando lo místico como experiencia puede ser el determinante para darle sentido a la vida, además es una alternativa en referencia al despliegue particular de las preocupaciones individuales que las ha refugiado exclusivamente en la exteriorización con el otro y con el mundo. El silencio, como proceso interno de convivencia de lo místico y lo determinable, situado en la cotidianidad, puede ser un estilo de vida, que entra en conflicto con el exceso comunicativo.

Ahora, vale preguntar ¿si lo indeterminable puede ser causa o móvil de lo determinable, es posible que se pueda generar un proceso contrario? Efectivamente sí, como por ejemplo la lectura de un libro puede invitar al lector a cerrarse a lo exterior y refugiarse en su silencio; que puede conllevar de por sí experiencias místicas, o por ejemplo en situaciones más críticas o delicadas como la muerte de algún ser querido, donde una de las alternativas para sobrellevar el sufrimiento propio de la condición humana es profundizar en los misterios propios de la vida, sea coadyuvado por alguna religión o no.

En conclusión, se puede indicar que el silencio como experiencia mística no es comunicable, pero sí causa o motor de situaciones comunicables. Ahora, este ejercicio es un rescate del ser como aquel que no solo es definible por sus manifestaciones sino también en aquello que nunca se expresa pero que existe y determina la vida del sujeto; queriendo decir con esto que la existencia personal es posible también desde aquello que se oculta de lo comunicable y del lenguaje mismo.

Por eso el silencio es la mejor manera de acercarse a lo más genuino para escapar del mundo de las definiciones que busca delimitar todo, dejando por fuera lo indeterminable. El silencio como experiencia mística es el primer paso para rebelarse frente a la represión de la determinación, donde todo pareciera estar encapsulado en conceptos, significantes y nominaciones, refugiándose así en el espectro de lo intangible, del misterio, de lo confuso; donde el silencio puede ser, como libre y genuino, el acto más feliz.

\section{Referencias}

Anadolu, A. (4 de abril de 2018). El árbol que inspiró a Issac Newton sigue firme. El Espectador, 1. 
Cadavid-Ramírez, L. M. (2014). Wittgenstein: lo místico en el Tractatus. Revista Fundación Universitaria Luis Amigó, 1(2), 126-136.

Carmona, C. (2015). Wittgenstein. La consciencia del límite. Madrid: Bonalletra Alcompas.

Cordua, C. (1998). Wittgenstein y los sentidos del silencio. Estudios Públicos, 70, 243-258.

Cuéllar Pérez, H. (2009). Hacia un nuevo humanismo: Filosofía de la vida cotidiana. En-claves del pensamiento, 3(5), 11-34.

Habermas, J. (1985). Teoría de la Acción Comunicativa. (M. Jiménez Redondo, trad.). Madrid: Taurus.

Jaramillo-Herrera, J. (2004). Apuntes sobre los juegos del lenguaje. Enunciación, 9(1), 37-45.

Magnavacca, S. (2005). Léxico Técnico de Filosofía Medieval. Madrid: Miño y Dávila editores.

Santander, J. R. (2000). El silencio de Wittgenstein. La lámpara de Diógenes, 1(1), 13-15.

Sierra, F. (1988). Filosofía de la comunicación. En torno a los medios. Revista Signo y Pensamiento, VII(13), 137-144.

Solares, B. (1996). La teoría de la acción comunicativa de Jürgen Habermas: tres complejos temáticos. Revista Mexicana de Ciencias Políticas y Sociales, 41(163), 9-33.

Wittgenstein, L. (2009). Tractatus Logico-Philosophicus. Investigaciones filosóficas. Sobre la certeza. Madrid: Gredos. 